Vol. 2, No. 1, Juni 2021

\title{
SPEKTA
}

Jurnal Pengabdian Kepada Masyarakat : Teknologi dan Aplikasi

Journal homepage :

http://journal2.uad.ac.id/index.php/spekta

\section{EFFORTS TO IMPROVE STUDENT UNDERSTANDING IN UTILIZING THE EFFICACY AND SAFETY OF TRADITIONAL DRUGS AT SMK PUTRA BANGSA SALATIGA}

\author{
Ahwan Abdul ${ }^{1, *}$, Mustaan $^{2}$, Anik Suwarni ${ }^{3}$ \\ ${ }^{1}$ Program Studi Farmasi, Universitas Sahid Surakarta, Surakarta, Jawa Tengah, Indonesia \\ ${ }^{2}$ Program Studi Ilmu Komunikasi, Universitas Sahid Surakarta, Surakarta, Jawa Tengah, Indonesia. \\ ${ }^{3}$ Program Studi Keperawatan, Universitas Sahid Surakarta, Surakarta, Jawa Tengah, Indonesia.
}

\begin{tabular}{l}
\hline ARTICLE INFO \\
\hline \\
Received : May, 2021 \\
Revised : June, 2021 \\
Accepted : June, 2021 \\
\hline
\end{tabular}

Keywords:

medicinal plants;

students;

vocational Schools;

utilization.

\begin{abstract}
Indonesia is a country that has the most plant biodiversity in the world, so that students and the government can take advantage of this biodiversity in preventing or adding complementary therapies to a disease. This utilization effort can increase the socio-economic level of Indonesian students. This service is carried out to be a solution to provide information and understanding to vocational students about the use, efficacy and safety of medicinal plants to assist the treatment process by utilizing the use of traditional medicinal plants, which schools only receive this information. So that vocational school graduates can later open their own business in the development of traditional medicines by knowing in advance the benefits, properties and safety of these traditional medicines. The method used in this service is through providing information on medicinal plants that are used as a preventive and promotive effort in treating existing diseases. This service is carried out to provide benefits, efficacy and safety to students of SMK Putra Bangsa Salatiga. Students get information about how to use medicinal plants in their environment so that they can be used if they have graduated or not
\end{abstract}

\section{PENDAHULUAN}

Obat tradisional indonesia adalah bahan/ramuan dari bahan tumbuhan, hewan, mineral, sediaan galenik dan campuran bahan - bahan tersebut digunakan secara turun temurun oleh nenek moyang indonesia yang mempunyai khasiat pengobatan, dan digunakan masyarakat indonesia. Obat tradisional sendiri dalam peraturan pemerintah

\footnotetext{
* Corresponding author.

E-mail address: ahwan@usahidsolo.ac.id

https://doi.org/10.12928/J.spekta.v2i1.4099
} 
Vol. 2, No. 1, Juni 2021

digolongkan menjadi jamu, Obat Herbal Terstandar (OHT) dan Fitofarmaka (Ningsih, 2016).

Pemanfaatan tanaman obat sendiri dilaksanakan oleh berbagai lapisan masyarakat dalam upaya dalam pencegahan dan pengobatan kesehetan. Terdapatnya tentang khasiat dan keamanan dari tanaman obat dapat mendorong penggunaan obat tradisional di masyarakat (Departemen Kesehatan RI, 2010b). Penelitian tersebut mencakup dalam bentuk tunggal dan ramuan obat tradisional (obat herbal), tetapi untuk penelitian uji klinik masih kurang sehingga data untuk khasiat dan keamanan (Novianto \& Saryanto, 2017).

Pemanfaatan obat tradisional sendiri sekarang sudah terasa sampai ke kota besar, yang dulunya hanya dimanfaatkan oleh masyarakat pedesaan yang hanya ada dikota kecil, sehingga manfaatnya sudah merata keseluruh kota di Indonesia (Dewi, Jamhari, \& Isnainar, 2017). Obat tradisional merupakan pilihan alternatif dalam pengobatan disebabkan pengobatan konvesional yang biayanya lebih mahal daripada pengobatan obat tradisional. Faktor lain selain biaya yaitu tingkat keamanan, mudah diperoleh dan kebosonan pemakaian obat kimia yang tidak menunjukkan hasil terapi yang lebih baik (Dewoto, 2007). Obat tradisional sendiri mempunyai khasiat untuk mencegah penyakit, mengobati penyakit ringan dan membantu mengobati penyakit berat, seperti Diabetes Melitus (DM), hipertensi, dislipidemia, kanker dan HIV (Subroto \& Harmanto, 2013). Dimasa pandemi ini maka diperlukan pemanfaatan obat-obatan yang dapat membuat tubuh menjadi lebih tahan terhadap penyakit (Arfan et al., 2020; Rahmawan \& Ma'ruf, 2020).

Beberapa penyuluhan terkait obat tradisional sudah banyak dilaksanakan. Beberapa penyuluhan tersebut yaitu penyuluhan obat tradisional pada lansia di Puskesmas Palanro Kabupaten Barru (Hendra Stevani, Mispari, Dewi, \& Setiawati, 2020). Selain itu ada penyuluhan tentang obat tradisonal di Desa Sigulang yang dilakukan oleh tim pengabdian Universitas Aufa Royhan (Yathurramadhan \& Yanti, 2020). Masyarakat Pulau Hiri juga mendapatkan penyuluhan tentang pemanfaatan obat tradisional dan pembuatan Hand Sanitizer dalam Pencegahan Covid-19 (Amran \& Ismail Rahman, 2020). Masyarakat Kelurahan Merdekan Kecamatan Kupang Timur juga mendapatkan hal serupa yaitu tentang pemanfaatan tanaman obat tradisional (Sambara, Yuliani, \& Emerensiana, 2016). Beberapa pengabdian dan penyuluhan yang sudah dilakukan, belum ada penyuluhan yang focus pada dunia pendidakn khususnya siswa SMK. Oleh karena itu pengabdian kali ini dilakukan untuk memberikan wawasan kepada siswa SMK di wilayah Salatiga jawa Tengah. Apalagi peran pengabdi sebagai sebagai tenaga pengajar dibidang kefarmasian adalah untuk membentuk lulusan terutama yang siap kerja yaitu lulusan SMK untuk membuka peluang kerja/wirausahawan yang bergerak dengan memanfaatkan tanaman obat tradisional yang ada menjadi suatu produk yang dapat berguna oleh masyarakat luas dalam meningkatkan upaya preventif dan promotif dalam meningkatkan derajat kesehatan.

Perkembangan obat tradisional sekarang ini dapat digunakan oleh siswa/siswi SMK dalam mencari peluang usaha, apabila lulus dari sekolah. pengabdian ini dilaksanakan dengan memberi informasi tentang tanaman obat indonesia yang bisa dimanfaatkan oleh siswa/siswi SMK dalam bentuk power point yang dilaksanakan didalam kelas.

\section{METODE PELAKSANAAN}

\section{A. Pendekatan}

Metode Pendekatan dalam pengabdian masyarakat ini secara umum terdapat lima target dan luaran yaitu: 
Vol. 2, No. 1, Juni 2021

1. Siswa/Siswi mampu mengetahui dan memahami Tanaman Obat apa saja yang dapat digunakan sebagai upaya promotif dan preventif dalam pengobatan.

2. Siswa/Siswi memahami dari keamanan (efek samping dan interaksi) tanaman obat.

3. Siswa/Siswi mampu mengaplikasikan atau membuat sediaan tanaman obat yang dapat digunakan secara aman dan efektif.

4. Siswa/Siswi dapat memanfatkan tanaman obat di sekitar lingkungan rumah dalam membantu pengobatan.

5. Siswa/siswi dapat membuka lapangan pekerjaan dengan membuka usaha sendiri dalam pemanfaatan tanaman obat alam.

Dari semua target ini pada akhirnya akan meningkatkan pengetahuan dan wawasan Siswa/Siswi SMK Putra Bangsa Kota Salatiga, dalam menggunakan dan memanfaatkan tanaman obat terutama tanaman obat dalam meningkatkan dari segi mutu dan ekonomi. Proses pengabdian ini dibagi menjadi dua tahapan yaitu:

a. Tahap 1

Pemaparan Tentang Tanaman Obat apa saja yang bisa dimanfaatkan meliputi khasiat, keamanan, dosis yang digunakan, cara menggunakan tanaman obat tersebut dan regulasinya (slide PPT dan Leaflet atau brosur).

b. Tahap 2

Dilakukan sesi tanya jawab, apakah Siswa/Siswi telah memperoleh informasi tentang tanaman obat dengan benar dan tepat atau Siswa/Siswi belum tahu tentang kegunaan tanaman obat tersebut.

\section{B. Rencana kegiatan}

Pelaksanaan pengabdian masyarakata terdiri dari beberapa tahap yaitu tahap persiapan, pelaksanaan, dan evaluasi.

\section{Persiapan}

Observasi ke lokasi mitra yaitu SMK Putra Bangsa Salatiga. Dalam tahap persiapan dilakukan proses perizinan dan penyampain tentang kegiatan pengabdian pada pihak SMK Putra Bangsa Salatiga dan Universitas Sahid Surakarta.

\section{Pelaksanaan Pengabdian}

Pada kegiatan ini, mitra akan mendapat pemaparan materi informasi tentang manfaat tanaman obat dalam pengobatan dan regulasi dari kebijakan pemerintah meliputi dari persiapan awal, pembagian leaflet, dan tanya jawab ke Siswa/Siswi.

\section{Evaluasi}

Tingkat keberhasilan pengabdian masyarakat ini dilakukan evaluasi (penilaian) meliputi:

a) Frekuensi kehadiran peserta pengabdian, dapat dilihat dari presensi kehadiran

b) Antusias peserta pegabdian cukup tinggi, ini dapat dilihat saat acara pemaparan materi.

c) Pada akhir acara pengabdian akan dilakukan pemantauan berkala terhadap keinginan atau masukan dari Siswa/Siswi tentang pengabdian ini.

\section{Penyusunan Laporan}

Data yang didapatkan dari hasil keseluruhan dari pengabdian masyarakat dibuat laporan pengabdian dan artikel pengabdian yang dipublikasi di jurnal pengabdian. 
Vol. 2, No. 1, Juni 2021

\section{Partisipasi Mitra Dalam Pengabdian Masyarakat}

Pihak mitra dalam pengabdian ini adalah SMK Putra Bangsa Salatiga. Mitra telah menyatakan bersedia untuk menyediakan tempat sosialisasi. Selain itu, peserta telah menyatakan bersedia untuk membagi ilmu serta ketrampilan yang diperoleh kepada Siswa/Siswi sekitar dan memanfatkannya dalam membantu sosialisasi dalam pengembangan tanaman obat indonesia.

\section{HASIL DAN PEMBAHASAN}

Kegiatan pengabdian Bagi Masyarakat dengan judul "Sosialisasi Dan Pemberian Materi Penggunaan, Pemanfaatan, Dan Keamanan Obat Tradisional Di Smk Putra Bangsa Kota Salatiga". diikuti Siswa/Siswi SMK Putra Bangsa Kota Salatiga. Pesertanya merupakan siswa/siswi SMK. Kegiatan pengabdian ini mendapat respon dan dukungan yang positif dari guru dan siswa/siswi SMK yang mengikuti kegiatan ini. Pada Kesempatan kali dihadiri guru wali dan BK dimana, pada kesempatan tersebut, beliau berterimakasih kepada Universitas Sahid Surakarta dan menyampaikan bahwa kegiatan pengabdian ini sangat bermanfaat untuk Siswa/Siswi SMK tersebut dalam memanfaatkan tanaman obat dilihat dari segi keamanan dan penggunaannya sehingga membantu para siswa/siswi untuk berkarya setelah lulus dari SMK Putra Bangsa.

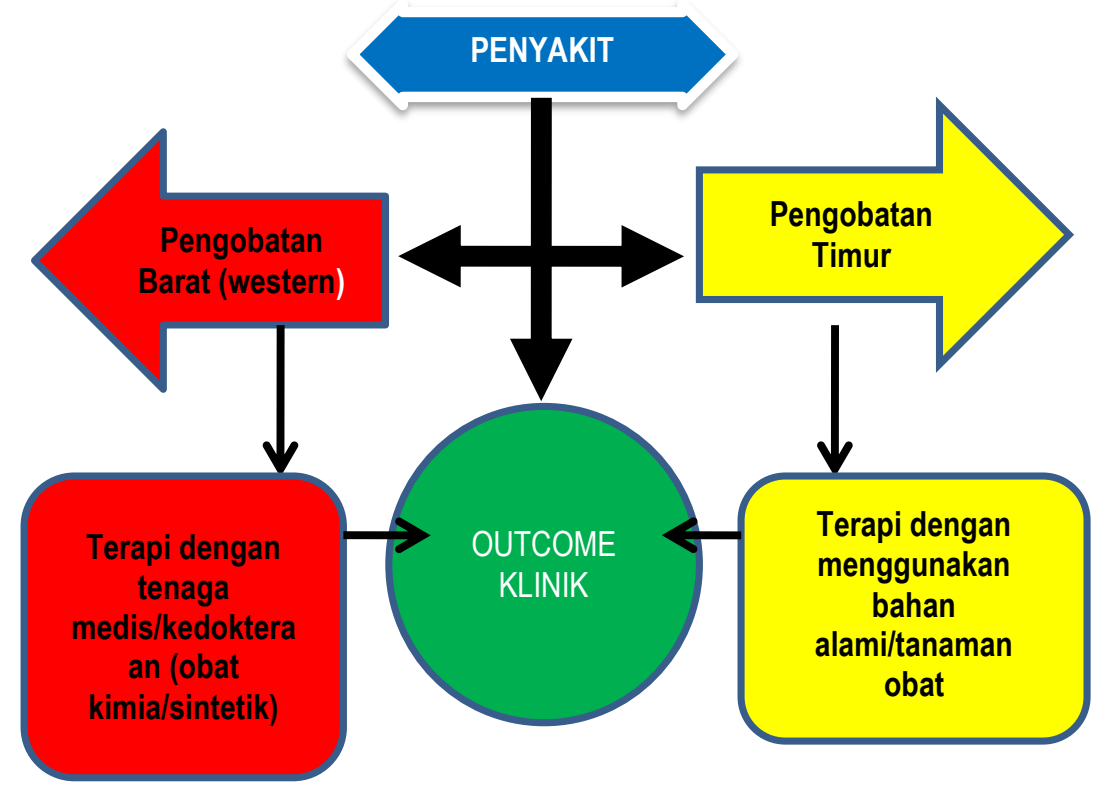

Gambar 1. Terapi Pengobatan Secara Konvesional dan Tradisional

Perkembangan obat tradisional/jamu di indonesia dikarenakan diperoleh turun temurun dari nenek moyang (empirik), back to nature (efek samping yg sedikit), banyak pasien obat barat yg beralih keobat tradisional, brand JAMU yang makin dikenal oleh masyarakat luar negeri, mulai diterapkan obat tradisional pada kalangan medis (dokter) saintifikasi jamu, penelitian yang dilakukan menambah evidance base pada penggunaan obat tradisional, jamu dapat berkembang menjadi Obat herbal Tersandar dan fitofarmaka, jamu yang berkembang dapat diterima oleh konsumen dalam dan luar negeri dalam MEA (Masyarakat Ekonomi Asean) dan daya saing produk dapat meningkat dari produk luar negeri (Laily, 2018). 
Vol. 2, No. 1, Juni 2021

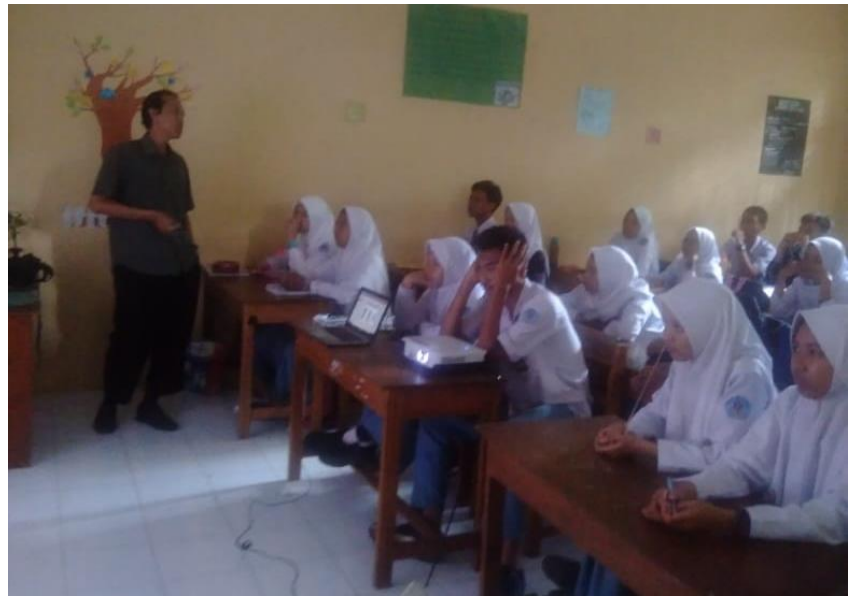

Gambar 2. Presentasi materi Pengabdian Masyarakat

Pembagian Obat tradisional sendiri menurut Depkes RI (2010) dibagi menjadi 3 bagian yaitu :

\section{a. Jamu}

Jamu merupakan obat tradisional yang aman, khasiat dapat dibuktikan secara empiris dan mempunyai mutu yang dapat dipertanggung jawabkan oleh regulasi yang berlaku di Indonesia. dalam penulisan klaim atau khasiat harus dicantumkan "Secara tradisional digunakan untuk ...".

\section{b. Obat Herbal Terstandarkan (OHT)}

Obat Herbal Terstandar merupakan obat tradisional yang harus aman, khasiat dibuktikan dengan uji pra klinik, bahan baku dan produk jadi sudah dilakukan standarisasi sehingga dapat menjamin mutu produk tersebut berdasrkan regulasi yang berlaku di Indonesia. Dalam penulisan klaim khasiat digunakan pembuktian umun dan medium.

\section{c. Fitofarmaka}

Fitofarmaka adalah obat tradisional yang aman digunakan, khasiat yang sidah dilakukan uji klink dan bahan baku serta produk jadi sudah dilakukan standarisasi sehingga mutu yang dihasilkan sesuai peraturan yang berlaku. Klaim fitofarmaka pada tingkat medium dan tinggi.




Vol. 2, No. 1, Juni 2021

Ramuan Saintifikasi Jamu: anti diabetes (sambiloto + daun salam), asam urat (daun seledri + rimpang temulawak + daun salam), kolesterol (daun jati belanda + rimpang temulawak + daun kemuning) dan hipertensi (daun seledri + daun pegagan + daun kumis kucing) (Departemen Kesehatan RI, 2010).

Kegiatan pengabdian masyarakat di SMK Putra Bangsa Kota Salatiga dilaksanakan dengan lancar dan baik. kegiatan ini diharapkan hubungan dengan mitra tetap terjalin baik, dan menjadikannya sebagai pusat binaan dengan cara mendorong siswa/siswi untuk menerapkan hasil pengabdian sebagai sarana dalam menambah pengetahuan tentang manfaat tanaman obat, meningkatkan kesadaran siswa/siswi akan manfaat tanaman obat, dengan memanfaatkannya menjadi sediaan obat untuk dikonsumsi sendiri, meningkatkan animo siswa/siswi desa dalam menggunakan obat tradisional dalam pemilihan terapinya dan membantu dan mendukung mitra dalam mewujudkan pemahaman masyrakat tentang tanaman obat.

\section{KESIMPULAN}

Kegiatan pengabdian pemanfaatan tanaman obat dalam membantu lulusan SMK Putra Bangsa Kota Salatiga untuk memperoleh informasi ke siswa/siswi dalam membuat sediaan obat tradisional yang bermanfaat dan aman bagi masyarakat luas, dan mencitai warisan nenek moyang Indonesia dalam menggunakan obat tradisional.Setelah melakukan pengabdian kepada siswa SMK Putra Bangsa Kota Salatiga ini diharapkan siswa-siswa dapat memperoleh informasi terkait kegunaan obat tradsional yang ada disekitar masyarakat maupun sekitar lingkungan masing-masing.

\section{DAFTAR PUSTAKA}

Amran, A. N., \& Ismail Rahman. (2020). Penyuluhan Pemanfaatan Obat Tradisional dan Pembuatan Hand Sanitizer dalam Pencegahan Covid-19 di Masyarakat Pulau Hiri. Jurnal Pengabdian UntukMu NegeRI, 4(2), 291-296.

Arfan, R., Hamdani, H., Puspita, D., Akbar, I., Ambartisari, G., \& Mirnawati, M. (2020). Peran ukm dalam menstabilkan harga masker sebagai bentuk pencegahan penyebaran covid-19 di banda aceh. SPEKTA (Jurnal Pengabdian Kepada Masyarakat: Teknologi Dan Aplikasi), 1(1), 31-34.

Departemen Kesehatan RI. (2010a). Peraturan Menteri Kesehatan Repunlik Indonesia No. 003/Menkes/Per/I/2010 tentang Saintifikasi Jamu Dalam Penelitian Berbasis Pelayanan Kesehatan. Jakarta.

Departemen Kesehatan RI. (2010b). Suplemen I: Farmakope Herbal Indonesia. Jakarta., Kementrian Kesehatan Republik Indonesia.

Dewi, N. K. L., Jamhari, M., \& Isnainar, I. (2017). Kajian Pemanfaatan Tanaman Sebagai Obat Tradisional Di Desa Tolai Kecamatan Torue Kabupaten Parigimoutong. E-JIP $B I O L, 5(2)$.

Dewoto, H. R. (2007). Pengembangan obat tradisional Indonesia menjadi fitofarmaka. Majalah Kedokteran Indonesia, 57(7), 205-211.

Hendra Stevani, Mispari, Dewi, R., \& Setiawati, H. (2020). Penyuluhan Penggunaan Obat Tradisional Kepada Lansia Puskesmas Palanro Kabupaten Barru. Jurnal Pengabdian Kefarmasian, 1(1), 23-26.

Laily, A. N. (2018). Etnobotani dan upaya mempertahankan tumbuhan bahan baku jamu gendong oleh masyarakat di Kecamatan Nguter Kabupaten Sukoharjo Provinsi 
Vol. 2, No. 1, Juni 2021

Jawa Tengah. Universitas Islam Negeri Maulana Malik Ibrahim.

Ningsih, I. Y. (2016). Studi etnofarmasi penggunaan tumbuhan obat oleh suku tengger di kabupaten lumajang dan malang, jawa timur. PHARMACY: Jurnal Farmasi Indonesia (Pharmaceutical Journal of Indonesia), 13(1), 10-20.

Novianto, F., \& Saryanto, S. (2017). Uji Klinik Fase II Ramuan Jamu Sebagai Pelindung Fungsi Hati. Indonesian Bulletin of Health Research, 45(2), 125-136.

Rahmawan, A., \& Ma'ruf, F. (2020). Pencegahan Demam Berdarah Pada Masyarakat Dusun Mongkrong Gunung Kidul. SPEKTA (Jurnal Pengabdian Kepada Masyarakat: Teknologi Dan Aplikasi), 1(1), 35.

Sambara, J., Yuliani, N. N., \& Emerensiana, M. Y. (2016). Pemanfaatan Tanaman Obat Tradisional Oleh Masyrakat Kelurahan Merdekan Kecamatan Kupang Timur 2016. Jurnal Info Kesehatan, 14(1), 1112-1124.

Subroto, A., \& Harmanto, N. (2013). Pilih jamu dan herbal tanpa efek samping. Elex Media Komputindo.

Yathurramadhan, H., \& Yanti, S. (2020). Penyuluhan Penggunaan Obat Tradisional Di Desa Labuhan Rasoki. Jurnal Education and Development, 8(1), 4-5. 
SPEKTA

Jurnal Pengabdian Kepada Masyarakat : Teknologi dan Aplikasi

Vol. 2, No. 1, Juni 2021

Halaman ini sengaja dikosongkan

This page is intentionally left blank. 